\title{
The Use of Panoramic Radiography to Determine Prevalence of Dental Anomaly in Individuals with Down Syndrome
}

\author{
Cek Dara Manja \\ Department of Dentomaxillofacial Radiology \\ Faculty of Dentistry, Universitas Sumatera Utara \\ Medan, Indonesia \\ cekdaramanja@yahoo.co.id
}

\author{
Nursyuhada Azimi \\ Faculty of Dentistry, Universitas Sumatera Utara \\ Medan, Indonesia
}

\begin{abstract}
Down syndrome often causes several dental anomalies, such as hypodontia, taurodontia and microdontia. This research aims to determine the prevalence of some dental anomalies in Down syndrome individuals using panoramic radiographs of students in Pembina disable school Medan. As many as 12 subjects with Down syndrome or 299 teeth identified by panoramic radiograph were used in this research. This was a descriptive research with cross sectional design. Sampling was selected by total sampling method. The radiographs were examined to determine the prevalence of hypodontia, taurodontia and microdontia, which were then calculated by descriptive test. Results showed 61 cases of taurodontia, 54 cases of microdontia and 3 cases of hypodontia. In conclusion, the prevalence of dental anomalies in individuals with Down syndrome using panoramic radiography is $20.40 \%$ of taurodontia, $18.06 \%$ of microdontia and $1.00 \%$ of hypodontia.
\end{abstract}

Keywords-Down syndrome, dental anomaly, panoramic radiograph

\section{INTRODUCTION}

Dental anomalies in individuals with Down syndrome can occur in both primary and permanent dentition, where it is found to be five times greater than in normal population [1]. According to Seagriff-Curtin et al, the most common dental anomalies associated with Down syndrome are variation in tooth number and morphology [2].

Talitha et al conducted a research in Brazil which showed that the highest prevalence of dental anomaly found in patients with Down syndrome was hypodontia with $34.5 \%$, microdontia with $9.4 \%$ and taurodontia with $3.1 \%$ [3]. The study of Mari Eli et al showed that in Brazil, dental anomalies in permanent and deciduous dentition can be identified using panoramic radiography and concluded that there was a high incidence of dental anomaly in individuals with Down syndrome and most were found with multiple anomalies [2].

The purpose of this study was to determine prevalence of dental anomalies in individuals with Down syndrome using panoramic radiography. Previous researches on dental anomalies of Down syndrome individuals using panoramic radiography had shown different results in different population.

\section{MATERIALS AND METHODS}

This was a descriptive research with cross sectional design. The study population was people with Down syndrome aged 12 years old and above in Pembina Special School, Jl. Karya Ujung, Medan.

The study sample is the entire population meeting inclusion criteria as population is small. The samples were selected with total sampling method. Inclusion criteria are down syndrome patients aged 12-26 years. Exclusion criteria are uncooperative down syndrome patients.

The equipment used in this research is panoramic radiography (Asahi) to obtain full oral view of patients with Down syndrome. The radiograph were then analyzed with viewer box and examined to determine the prevalence of some dental anomalies such taurodontia, hypodontia and microdontia. The results were then calculated with descriptive test. Ethical clearance of this study was obtained from the Research Ethics Committees of Faculty of Medicine, University of Sumatera Utara.

\section{RESULTS}

In 12 samples of panoramic radiographs, hypodontia occurred in three samples involving three teeth of permanent dentition, usually maxillary lateral incisors and mandibular lateral incisors. Microdontia appears to involve 44 permanent teeth which varies from the maxillary central incisor to the second premolar of the mandible. The most commonly affected teeth of microdontia are mandibular central incisors with a percentage of $27.78 \%$. Taurodontia was found in all samples and involved 61 teeth, varying from maxillary central incisors to the mandibular second molars. The teeth most commonly affected by taurodontia are maxillary first molars with a percentage of $22.95 \%$ (Table I). 
TABLE I. DISTRIBUTION OF PERMANENT TEETH WITH HYPODONTIA, MICRODONTIA AND TAURODONTIA

\begin{tabular}{|c|c|c|c|}
\hline Dental Anomaly & Tooth & $\mathbf{n}$ & $\%$ \\
\hline \multirow[t]{3}{*}{ Hypodontia } & I2 Mx & 1 & 33.33 \\
\hline & I2 Md & 2 & 66.67 \\
\hline & TOTAL & 3 & 100 \\
\hline \multirow[t]{11}{*}{ Microdontia } & I1 Mx & 4 & 7.41 \\
\hline & I1 Md & 15 & 27.78 \\
\hline & I2 Mx & 3 & 5.56 \\
\hline & I2 Md & 8 & 14.81 \\
\hline & $\mathrm{C} \mathrm{Mx}$ & 1 & 1.85 \\
\hline & $\mathrm{C} \mathrm{Md}$ & 5 & 9.26 \\
\hline & P1 Mx & 2 & 3.70 \\
\hline & P1 Md & 2 & 3.70 \\
\hline & P2 Mx & 3 & 5.56 \\
\hline & P2 Md & 1 & 1.85 \\
\hline & TOTAL & 44 & 81.50 \\
\hline \multirow[t]{13}{*}{ Taurodontia } & I1 Mx & 5 & 8.20 \\
\hline & I2 Md & 2 & 3.28 \\
\hline & $\mathrm{C} \mathrm{Mx}$ & 1 & 1.64 \\
\hline & $\mathrm{C} \mathrm{Md}$ & 3 & 4.92 \\
\hline & P1 Mx & 2 & 3.28 \\
\hline & P1 Md & 3 & 4.92 \\
\hline & $\mathrm{P} 2 \mathrm{Mx}$ & 1 & 1.64 \\
\hline & P2 Md & 5 & 8.20 \\
\hline & M1 Mx & 14 & 22.95 \\
\hline & M1 Md & 13 & 21.31 \\
\hline & M2 Mx & 5 & 8.20 \\
\hline & M2 Md & 5 & 8.20 \\
\hline & TOTAL & 59 & 96.72 \\
\hline
\end{tabular}

Distribution deciduous teeth with microdontia in Down syndrome patients are found to affect various teeth from mandibular central incisors to the first molar maxilla with percentage of $18.50 \%$. Taurodontia occurs only in the mandibular first molars $(3.28 \%)$ (Table II).

TABLE II. DISTRIBUTION OF PRIMARY TEETH WITH MICRODONTIA AND TAURODONTIA

\begin{tabular}{|l|l|l|l|}
\hline Dental Anomaly & \multicolumn{1}{|c|}{ Tooth } & $\mathbf{n}$ & \multicolumn{1}{c|}{$\%$} \\
\hline Microdontia & $\mathrm{I} 1 \mathrm{Md}$ & 2 & 3.70 \\
\cline { 2 - 4 } & $\mathrm{I} 2 \mathrm{Mx}$ & 2 & 3.70 \\
\cline { 2 - 4 } & $\mathrm{I} 2 \mathrm{Md}$ & 2 & 3.70 \\
\cline { 2 - 4 } & $\mathrm{C} \mathrm{Mx}$ & 1 & 1.85 \\
\cline { 2 - 4 } & $\mathrm{C} \mathrm{Md}$ & 2 & 3.70 \\
\cline { 2 - 4 } & M1 Mx & 1 & 1.85 \\
\cline { 2 - 4 } & TOTAL & $\mathbf{1 0}$ & $\mathbf{1 8 . 5 0}$ \\
\hline Taurodontia & M1 Md & 2 & 3.28 \\
\hline & TOTAL & $\mathbf{2}$ & $\mathbf{3 . 2 8}$ \\
\hline
\end{tabular}

Dental anomalies identified using panoramic radiography in individuals with Down syndrome are hypodontia, microdontia and taurodontia, involving 118 teeth of 299 teeth (Table III).

TABLE III. PERCENTAGE OF HYPODONTIA, MICRODONTIA AND TAURODONTIA IN INDIVIDUALS WITH DOWN SYNDROME

\begin{tabular}{|c|c|c|}
\hline \multirow[t]{2}{*}{ Dental Anomaly } & \multicolumn{2}{|c|}{ Down Syndrome Subjects } \\
\hline & $n$ & $\%$ \\
\hline Hypodontia & 3 & 1.00 \\
\hline Microdontia & 54 & 18.06 \\
\hline Taurodontia & 61 & 20.40 \\
\hline Others & 181 & 60.54 \\
\hline TOTAL & 299 & 100 \\
\hline
\end{tabular}

\section{DISCUSSION}

This research proved that taurodontia was the highest dental anomaly affecting Down syndrome patients with the percentage of $20.40 \%$ or 61 tooth. Similar to the study of Moraes et al, which proved that the frequency of taurodontia in Down syndrome patients was the highest with percentage of $85.71 \%$ [2]. Permanent maxillary first molar, followed by mandibular first molar were the highest affected by taurodontia with the percentage of $22.95 \%$ or 14 tooth and $21.31 \%$ or 13 tooth respectively. Unlike this research, Park et al said that mandibular first molar was the highest affected by taurodontia on patients without syndrome in Korea [4]. This might be due to the syndrome factor in Down syndrome patients.

This study proved that microdontia was the second highest dental anomaly affecting Down syndrome individuals with $18.06 \%$ or 54 tooth. Permanent mandibular central incisal was most commonly affected by microdontia with $27.78 \%$ or 15 out of 54 tooth, followed by permanent mandibular lateral incisal with the percentage of $14.81 \%$ or 8 out of 54 tooth. This is similar to the study of Mellara et al, which also proved that microdontia was the second highest dental anomaly affecting Down syndrome patients with the percentage of $9.4 \%$ [4]. Another study by Gupta $\mathrm{S}$ et al also proved that microdontia often affected maxillary teeth compared to mandibular teeth [5]. This might be due to the factor of contributing to the occurrence of microdontia, which are genetic and environment factors [5]. Previous studies were conducted in several different countries, where different environmental factors might result in different results. In addition, this study was conducted on Down syndrome patients with unknown genetics history, which might affect the occurrence of microdontia. Hypodontia was found to be the rarest dental anomaly found on Down syndrome patients by $1.00 \%$ or three tooth. Two out of three was mandibular lateral incisal $(66.67 \%)$ and one left was maxillary lateral incisal $(33.33 \%)$.

This study is different from Mellara et al which showed hypodontia was the highest dental anomaly found on Down syndrome patients in Brazil by $35.4 \%$. This is similar to the study of Mellara et al which stated that the most frequent tooth affected by hypodontia was maxillary and mandibular lateral incisal [3]. According to Kotecha $\mathrm{S}$, age, ethnic and genetic are factors affecting the prevalence of hypodontia. Prevalence of hypodontia in the youth are lower compared to adult [6]. This study was conducted on subjects with the mean age of 12 years old, while the study of Mellara TS et al was conducted on sample with the mean age of 20 years old. Prevalence of hypodontia on Asian are lower compared to Middle East and English [6]. Mellara TS et al research was conducted on American Latin and Asian. Prevalence of hypodontia is higher in individuals with contributing genetic factors (50\% to normal 6\%) [6]. This study was conducted without considering environment and genetic factors which might affect the condition of dental anomaly in down syndrome patients. 
In conclusion, the prevalence of some dental anomalies on Down syndrome individuals, aged 12-26 years old with total sample of 12 or 299 tooth are $20.40 \%$ taurodontia (12 samples with 61 teeth), 18.06 $\%$ microdontia (9 samples with 54 teeth) and $1.00 \%$ hypodontia (3 samples with 3 teeth).

\section{REFERENCES}

[1] R.H.W. Cheng, C.K.Y. Yiu, W.K. Leung, Prenatal diagnosis and screening for down syndrome. China: In Tech, pp. 63-71, 2011.

[2] M.E.L. Moraes, L.C. Moraes, G.N. Dotto, "Dental anomalies in patients with down syndrome," Braz Dent J., vol. 18, no. 4, pp. 346-350, 2007
[3] T.S. Mellara, L.C. Pardini, F.P. Nelson, "Occurence of hypodontia, supernumerary teeth and dental anomalies in Brazilian individuals with down syndrome," J. Od Disability and Oral Health, vol. 12(1), pp. 31, 2011.

[4] H. Jafarzadeh, A. Azarpazhooh, J.T. Mayhall, "Taurodontism: A review of the condition and endodontic treatment challenges,' Int. Endodontic J., vol. 41, pp. 375, 377, 382, 2008.

[5] S. Gupta, K.N. Garg, O.P. Gupta, "Non syndromic true localized microdontia of permanent central incisor - a case report," Indian J. of Dental Sciences, vol. 4, pp. 964-965, 2012.

[6] S. Kotecha, The impact of hypodontia on the oral health-related quality of life in children. Birmingham: University of Birmingham, pp. 5, 8, 11, 2011 . 